\title{
Using Lithium Glass Infiltration to Enhance the Properties of Alumina Bodies
}

\author{
Wilson Acchar*, José Renato Cavalcanti de Queiroz \\ Programa de Pós-graduação em Ciência e Engenharia de Materiais, \\ Universidade Federal do Rio Grande do Norte - UFRN \\ Bairro Lagoa Nova, 59072-970 Natal - RN, Brazil
}

Received: June 6, 2008; Revised: November 3, 2008

\begin{abstract}
The use of an infiltration process to improve the properties of sintered materials has been widely investigated. This work describes the research carried out in the manufacturing of lithium glass-infiltrated alumina. The infiltration material consisted of a mixture of elements such as $\mathrm{Li}_{2} \mathrm{O}, \mathrm{ZrO}_{2}, \mathrm{SiO}_{2} \mathrm{Al}_{2} \mathrm{O}_{3} \mathrm{CaO}$ and $\mathrm{La}_{2} \mathrm{O}_{3}$. Alumina specimens were sintered in air at $1400^{\circ} \mathrm{C}$ for 2 hours. A number of samples were then submitted to the infiltration process at $1400{ }^{\circ} \mathrm{C}$ for 15 minutes. Sintered and infiltrated specimens were characterized by X ray diffraction, apparent density, open porosity, flexural strengths and scanning electron microscopy. The results showed that the infiltration process considerably improves the properties of alumina bodies.
\end{abstract}

Keywords: glass infiltration, mechanical properties and lithium glass material

\section{Introduction}

The sintering stage is the most important phase in the manufacturing process of any ceramic material, mainly where energy costs are concerned. It is well known that the sintering process of alumina and other ceramic materials can be improved by using finer particles (nanotechnology), particles with higher reactivity and sintering additives ${ }^{1-3}$. An alternative method that has been investigated to achieve a dense material is the use of an infiltration process in a porous ceramic $\mathrm{c}^{4-8}$. The most commonly used technique to obtain a porous ceramic involves sintering the material until incomplete densification (low or insufficient sintering temperature). The glass infiltration technique can improve the mechanical properties of the alumina material owing to the increase in density of the ceramic material, the generation of compressive residual stress on the surface and the blunting of fine surface cracks produced by the sintering and machining process ${ }^{3}$. Positive capillary pressure, which occurs when a molten glass material comes into contact with a solid ceramic, is responsible for pressureless infiltration. A number of researchers have also observed the positive effect of the infiltration of metallic elements or alloys such as $\mathrm{Si}, \mathrm{Al}, \mathrm{Al} / \mathrm{Si}, \mathrm{Al} / \mathrm{Mg}$ in a porous material ${ }^{9-11}$. Another interesting technique to obtain full interpenetrating networks at low porosities is the use of a slip-cast ceramic suspension in polymeric foam. This method consists of the impregnation of a polymeric foam with a ceramic slurry followed by a burnout of the organic material and the sintering of the ceramic skeleton. The resulting material is a negative replica of the foam with fully open porosity $y^{5,12,13}$. The composite materials obtained by this technique have low shrinkage, good properties and homogeneous microstructure ${ }^{6,7}$. Alumina-glass materials obtained by the infiltration process have been widely studied in recent decades ${ }^{3-8}$. This class of materials is characterized by low shrinkage, good mechanical properties and homogeneous structure ${ }^{6}$, making it ideal for studying the potential use of new glass material. As a consequence of the different requirements, different glass ceramic systems such as $\mathrm{SiO}_{2}-\mathrm{CaO}-\mathrm{Na}_{2} \mathrm{O}-\mathrm{P}_{2} \mathrm{O}_{5}, \mathrm{SiO}_{2}-\mathrm{CaO}-\mathrm{MgO}-\mathrm{P}_{2} \mathrm{O}_{5}-\mathrm{F}, \mathrm{SiO}_{2}-$ $\mathrm{Al}_{2} \mathrm{O}_{3}-\mathrm{MgO}-\mathrm{CaO}-\mathrm{Na}_{2} \mathrm{O}-\mathrm{K}_{2} \mathrm{O}-\mathrm{P}_{2} \mathrm{O}_{5}-\mathrm{F}, \mathrm{SiO}_{2}-\mathrm{CaO}-\mathrm{P}_{2} \mathrm{O}_{5}, \mathrm{SiO}_{2}-\mathrm{Al}_{2} \mathrm{O}_{3}-$ $\mathrm{MgO}-\mathrm{K}_{2} \mathrm{O}-\mathrm{ZrO}_{2}-\mathrm{CeO}_{2}$ and the lanthanum borosilicate system have been investigated ${ }^{6,14}$. Another recent work has indicated the enhancing effect of borosilicate glass on the tribological properties of alumina ${ }^{4}$. A sintered glass material belonging to the $\mathrm{Li}_{2} \mathrm{O}-\mathrm{ZrO}_{2}-\mathrm{SiO}_{2}-\mathrm{Al}_{2} \mathrm{O}_{3}(\mathrm{LZSA})$ system has recently been investigated using an extrusion process and the replication method ${ }^{15,16}$. This lithium glass ceramic material (LZSA) has shown high thermal shock strength and a low thermal expansion coefficient ${ }^{15}$, making its use ideal for a number of applications such as cylindrical pieces for pass wire in the textile industry, industrial filtration processes for particulate matter removal, dust and smoke and gas fumes up to $600{ }^{\circ} \mathrm{C}^{15,16}$. These results suggest that this glass system has good potential and should be further investigated, especially owing to its low cost and low sintering temperature. Studies on the use of lithium-based glass material for infiltration processes are still scarce. The aim of this study was to investigate the prospective use of the infiltration of a glass material consisting of LZSA with additions of $\mathrm{CaO}$ and $\mathrm{La}_{2} \mathrm{O}_{3}$ into alumina bodies.

\section{Experimental Procedure}

\subsection{Alumina ceramic preparation}

Alumina APC-2011 (Alcoa, Brazil) with an average grain size of $2.3 \mu \mathrm{m}$ was used as the ceramic matrix. A glass composition belonging to the $\mathrm{Li}_{2} \mathrm{O}-\mathrm{ZrO}_{2}-\mathrm{SiO}_{2}-\mathrm{Al}_{2} \mathrm{O}_{3}$ system with additions of $15 \mathrm{wt}$.(\%) $\mathrm{CaO}$ or $\mathrm{La}_{2} \mathrm{O}_{3}$ was prepared from commercially available raw materials. Details of LZSA preparation were described in a previous work ${ }^{17}$. $\mathrm{CaO}$ and $\mathrm{La}_{2} \mathrm{O}_{3}$ were added to the LZSA to promote better penetration of the molten glass into the porous ceramic matrix. The alumina powder was uniaxially pressed into prismatic bars $\left(30 \times 5 \times 5 \mathrm{~mm}^{3}\right)$ under a load of $20 \mathrm{MPa}$. Powder compact was pressureless sintered at $1400{ }^{\circ} \mathrm{C}$ for 2 hours in a tubular furnace.

\subsection{Infiltration technique}

A glass layer was applied to the surface of the sintered material. The infiltrated materials were then heated in a vacuum oven at $1400{ }^{\circ} \mathrm{C}$ for 15 minutes, where the material melted and penetrated into the porous sample. This infiltration process was repeated twice. The sample was inverted and a second glass layer was applied to the other side. The physical properties of the investigated materials were determined after the sintering process and after the first and second infiltration steps. 


\subsection{Characterization of the sintered and infiltrate materials}

The apparent density and porosity of the sintered and infiltrated materials were determined using Archimedes's water displacement method, as specified by European Standard EN 99 (ISO 10545-3, $1991)^{18}$. Crystalline phases were identified by X ray diffraction (Schimadzu XRD-600) with angles ranging between 15 and $80^{\circ}$ with a scanning rate of $2^{\circ}$ per minute. The mechanical strength of both materials was determined from the average of five measurements for each case, using a universal testing machine (Zwick-Roell) in a four point bending geometry, with an upper and bottom knife span of 20 and $10 \mathrm{~mm}$, respectively, at a constant cross-head speed of $0.4 \mathrm{~mm} / \mathrm{min}$. The microstructure of the samples before and after infiltration was studied by scanning electron microscopy (Philips XL-30) to determine infiltration efficiency.

\section{Results and Discussion}

Figure 1 shows the $\mathrm{X}$ ray diffraction patterns of all the investigated materials. Figure 1a shows that the LZSA glass material exhibits amorphous behavior, with no well-defined crystalline peaks. This amorphous nature is characteristic of the glassy state. As expected, the noninfiltrated sintered alumina shows only the presence of the $\mathrm{Al}_{2} \mathrm{O}_{3}$ crystalline phase (Figure 1b). Both infiltrated materials $\left(\mathrm{LZSA}+\mathrm{CaO}\right.$ and $\mathrm{LZSA}+\mathrm{La}_{2} \mathrm{O}_{3}$ ) show the presence of $\mathrm{Al}_{2} \mathrm{O}_{3}, \mathrm{ZrO}_{2}$, $\mathrm{LiAlSi}_{2} \mathrm{O}_{6}$ and $\mathrm{LiSiO}_{3}$ (Figure 1c and 1d), which is in agreement with other studies ${ }^{14,15}$. The addition of $\mathrm{CaO}$ or $\mathrm{La}_{2} \mathrm{O}_{3}$ had no effect on the $\mathrm{X}$ ray diffraction pattern. No other crystalline phases were identified. Figure 2 shows porosity values as a function of the infiltration step. It is clear that the infiltration process caused a significant decrease in open porosity, regardless of the presence of $\mathrm{CaO}$ or $\mathrm{La}_{2} \mathrm{O}_{3}$. The infiltration of the glass material by capillary forces caused a filling of the internal pores, leading to a decrease in porosity from 40 to $30 \%$ in the first infiltration and to $10 \%$ in the second infiltration.

Table 1 summarizes the properties obtained in this work. As can be seen the infiltrated materials have higher strength values than those of uninfiltrated ceramic bodies

The second infiltration caused a marked increase in strength values ( 210 MPa) compared to the pure alumina (24 MPa). This may be associated to surface defect healing of the specimens. These results confirm the positive effect of LZSA glass infiltration. Published studies also describe the positive effect of the infiltration of different glass systems on the strength and fracture toughness of alumina

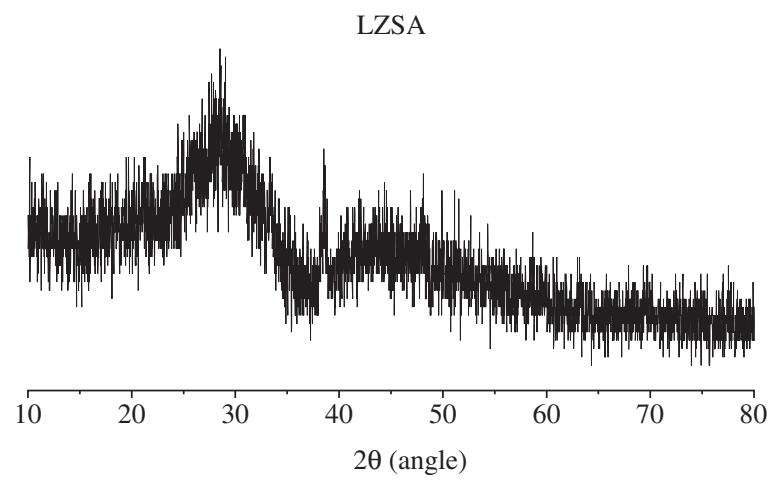

(a)

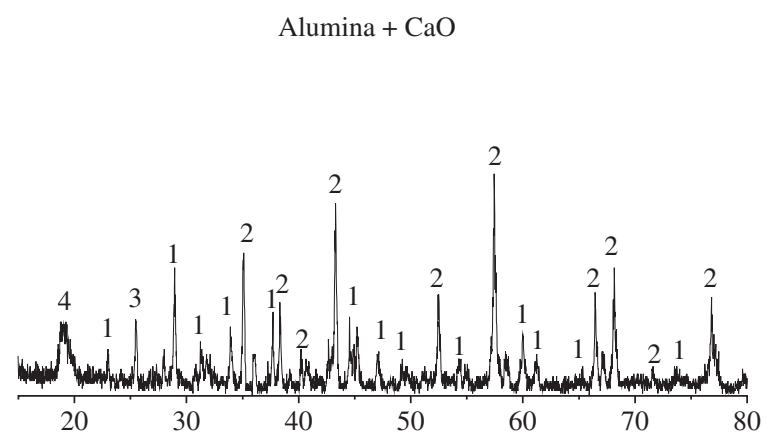

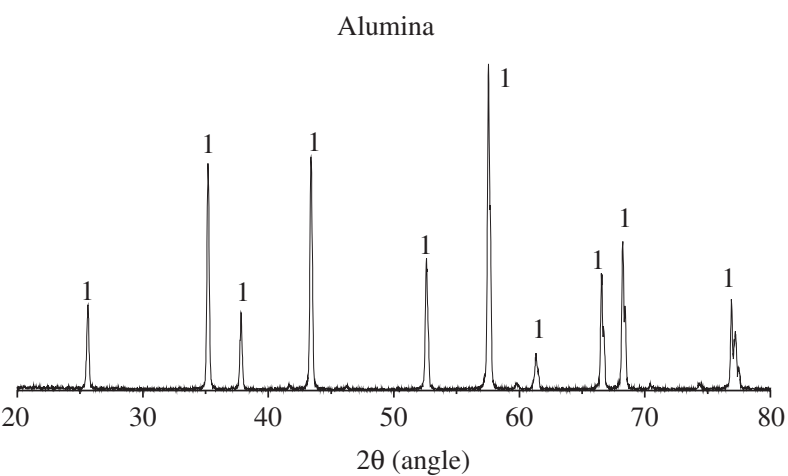

1) Alumina

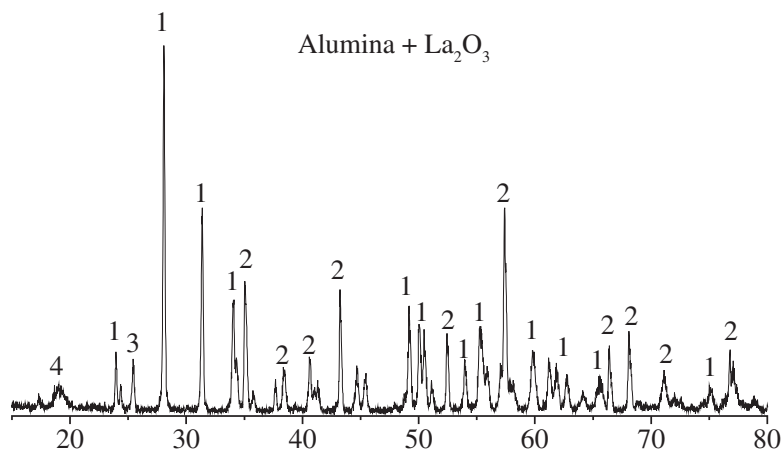

$2 \theta$ (angle)

1) Alumina

2) $\mathrm{ZrO}_{2}$

3) $\mathrm{LiA}_{1} \mathrm{Si}_{2} \mathrm{O}_{2}$

4) $\mathrm{Li}_{2} \mathrm{SiO}_{3}$

(d)

Figure 1. $\mathrm{X}$ ray diffraction pattern of a) LZSA; b) $\mathrm{Al}_{2} \mathrm{O}_{3}$; c) $\mathrm{Al}_{2} \mathrm{O}_{3}+\mathrm{CaO}$; and d) $\mathrm{Al}_{2} \mathrm{O}_{3}+\mathrm{La}_{2} \mathrm{O}_{3}$. 


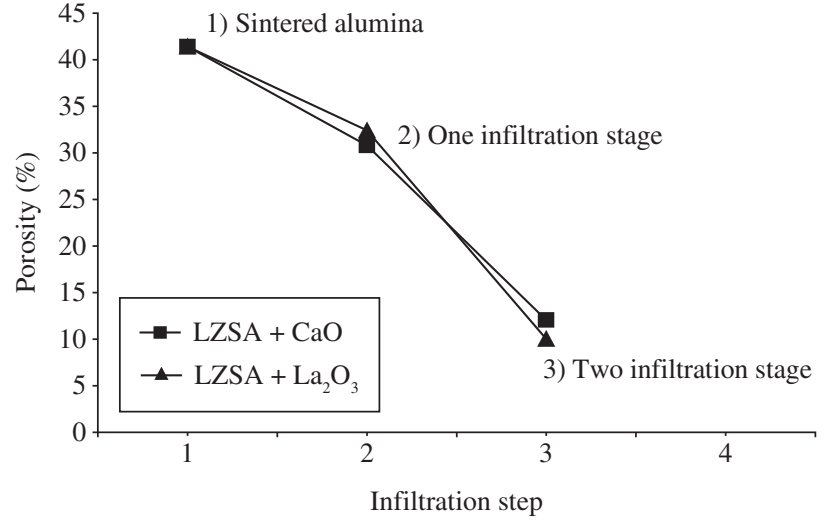

Figure 2. Porosity values of the investigated materials.

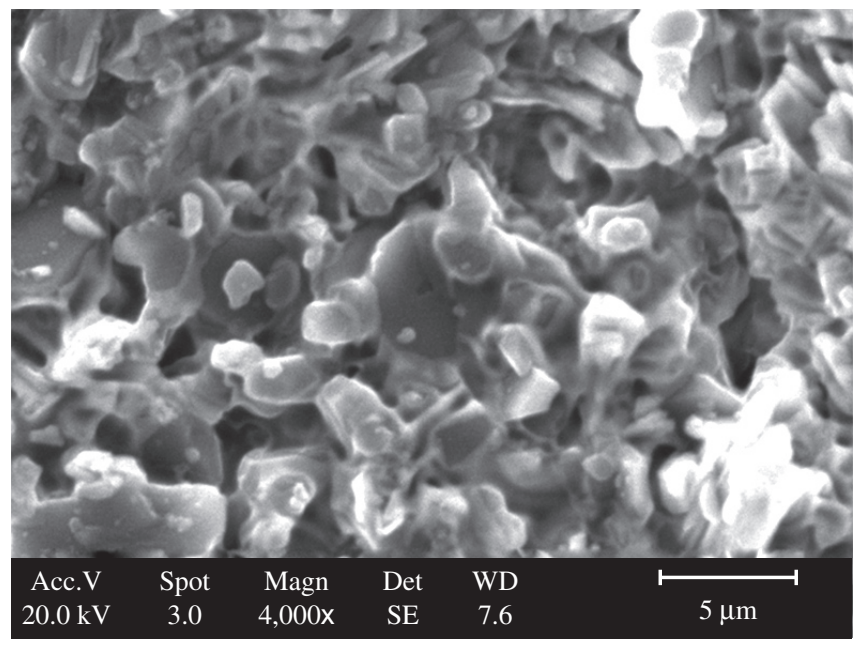

(a)

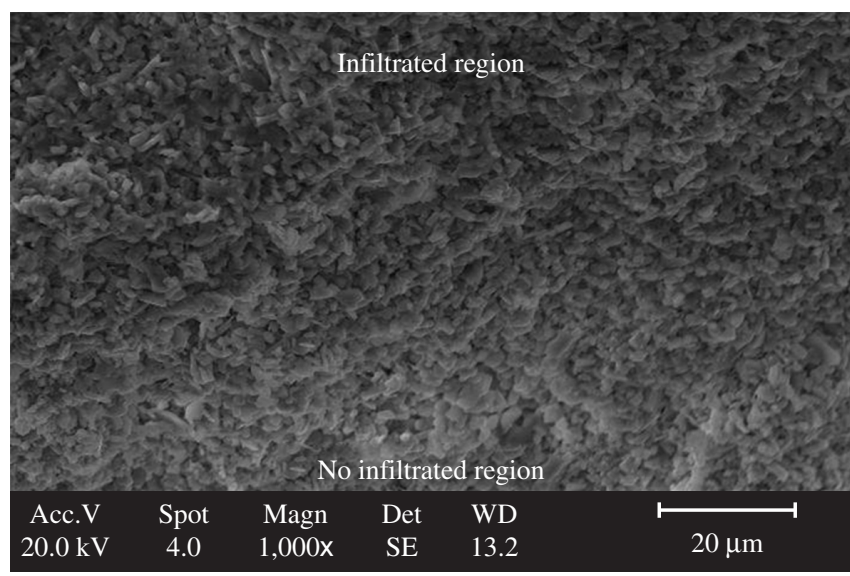

(c)
Table 1. Physical and mechanical properties of alumina bodies after sintering and infiltration processes.

\begin{tabular}{lccc}
\hline \multicolumn{1}{c}{ Materials } & $\begin{array}{c}\text { Density } \\
\left(\mathrm{g} / \mathrm{cm}^{3}\right)\end{array}$ & $\begin{array}{c}\text { Porosity } \\
(\%)\end{array}$ & $\begin{array}{c}\text { Strength } \\
(\mathrm{MPa})\end{array}$ \\
\hline $\begin{array}{l}\text { Sintered alumina } \\
\text { Sintered alumina infiltrated } \\
\text { with LZSA-CaO }{ }^{1}\end{array}$ & 2.30 & 41.40 & $24 \pm 3$ \\
$\begin{array}{l}\text { Sintered alumina infiltrated } \\
\text { with LZSA- } \mathrm{La}_{2} \mathrm{O}_{3}{ }^{1}\end{array}$ & 2.50 & 30.80 & $95 \pm 11$ \\
$\begin{array}{l}\text { Sintered alumina infiltrated } \\
\text { with LZSA-CaO }\end{array}$ & 3.08 & 12.07 & $204 \pm 17$ \\
$\begin{array}{l}\text { Sintered alumina infiltrated } \\
\text { with LZSA- } \mathrm{La}_{2} \mathrm{O}_{3}{ }^{2}\end{array}$ & 3.40 & 10.02 & $235 \pm 22$ \\
\hline
\end{tabular}

${ }^{1}$ one-infiltration stage, ${ }^{2}$ two-infiltration stage.

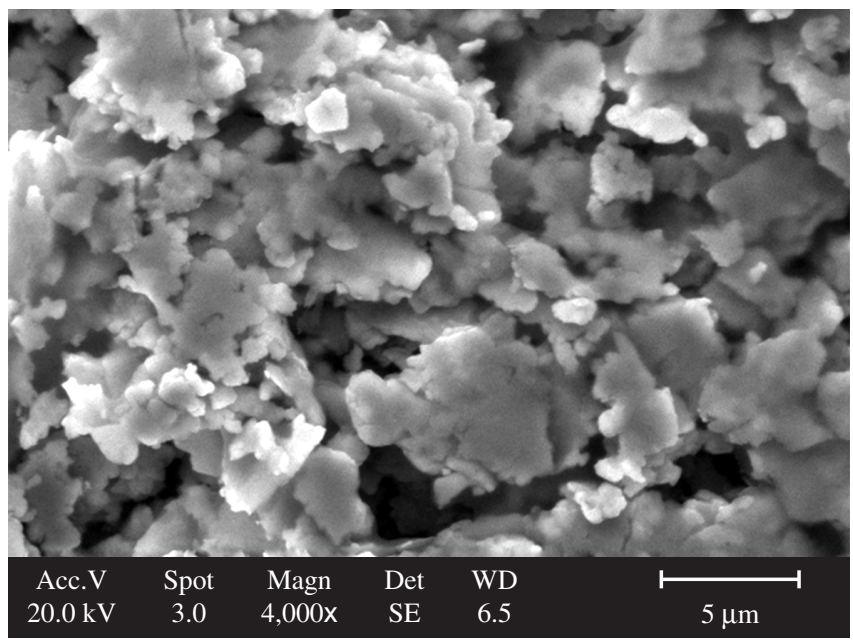

(b)

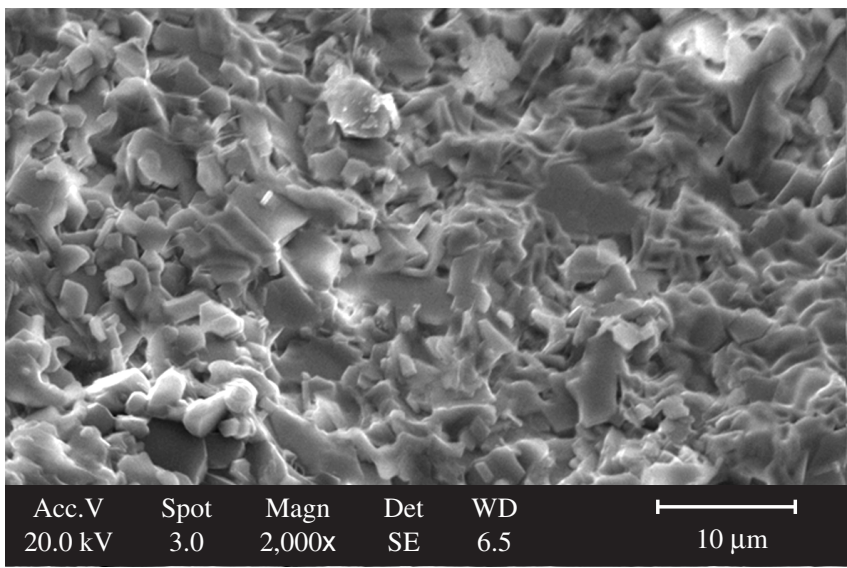

(d)

Figure 3. Micrograph showing the aspects of: a) infiltrated sample; a) uninfiltrated sample; c) infiltrated and uninfiltrated regions in the same sample; and d) surface fracture.

bodies $^{4,7}$ and polymer composites ${ }^{5}$. It is well known that mechanical behavior is dependent on factors such as grain size, crystalline content and sample size. Given that the samples described in the literature were significantly smaller $\left(20 \times 1.2 \times 4 \mathrm{~mm}^{3}\right)$ than those used in this study, the resulting strength values were higher. SEM images of the lithium glass alumina material after infiltration are shown in Figure 3. Figures $3 \mathrm{a}$ and $3 \mathrm{~b}$ compare microstructural aspects of the infiltrated and noninfiltrated specimens. Microscopy shows marked differences between the two materials. Compared to the noninfiltrated sample, the microstructure of the lithium glass phase region seems to have smaller pores uniformly distributed in the matrix and a lower presence of voids, which is characteristic of an incomplete sintering process.

Figure $3 \mathrm{c}$ shows the difference between the infiltrated and noninfiltrated area in the same sample (Figure $3 \mathrm{c}$ ). The infiltrated region 
shows a more homogeneous and denser region, which is characteristic of a pronounced filling of the pores produced by the infiltration of the glass phase. The noninfiltrated area has a lower densification level and is characterized by non- penetration of the glass phase. This result confirms that the lithium glass investigated in this work penetrated into the porous alumina, filling the pores and contributing to the increase in alumina matrix properties. Figure $3 \mathrm{~d}$ shows the fracture surface of the glass-infiltrated material. It can be seen that the fracture mode is predominantly transgranular. The microstructure also shows smaller pores homogeneously distributed in the matrix.

\section{Conclusions}

Pressureless infiltration of $\mathrm{Al}_{2} \mathrm{O}_{3}$ performed with a lithium glass allowed us to obtain dense samples at low temperatures with good properties. Glass infiltration significantly improved the density, open porosity and bending strength of the alumina, showing that the LZSA glass system warrants further investigation. The beneficial effect produced by glass infiltration may be attributed to the healing of defects obtained by glass flow.

\section{References}

1. Dorre E, Huebner H. Alumina: Processing and Applications. Berlin: Springer; 1984.

2. Acchar W, Ramalho EG, Hotza D, Segadaes AM. Using granite rejects to aid densification and improve mechanical properties of alumina bodies. Journal Materials Science 2005; 40 (15):3905-3909.

3. Guazzato M, Albakry M, Quach L, Swain MV. Influence of surface and heat treatments on the flexural strength of a glass-infiltrated alumina/zirconia-reinforced dental ceramic. Dental Materials 2005; 21 (5):454-463.

4. Sarkar D, Basu B, Chu MC, Cho SJ. In glass infiltration beneficial to improve fretting wear properties for alumina. Journal of American Ceramic Society 2007; 90 (2):523-530.

5. Peitl O, Orefice RL, Hench LL, Brennan AB. Effect of the cystalization of bioactive glass reinforcing agents on the mechanical properties of polymer composites. Materials Science \& Engineering 2004; A372 $(1-2): 245-251$.
6. Sheng XJ, Xu H, Jin ZH, Wang YL. Preparation of glass-infiltrated 3 Y-TZP/A12O3/glass composites. Materials Letters 2004; 58 (11):1750-1753

7. Guazzato M, Albakry M, Ringer SP. Strength, fracture toughness and microstructure of a selection of al-ceramic materials. Part I. Pressable and alumina glass-infiltrated ceramics. Dental Materials 2004; 20 (5):441-448.

8. Mattern A, Huchler B, Staudenecker D, Oberacker R, Nagel A, Hoffmann MJ. Preparation of interpenetrating ceramic-metal composites. Journal European Ceramic Society 2004; 24 (12):3399-3408.

9. Rao BS, Jayaram V. Pressureless infiltration of Al-Mg based alloys into $\mathrm{Al}_{2} \mathrm{O}_{3}$ preforms:mechanisms and phenomenology. Acta Materialia 2001; 49 (13):2373-2385.

10. Kevorkijan VM. The reactive infiltration o porous ceramic media by a molten aluminum alloy. Composites Science and Technology 1999; 59 (5):683-686.

11. Travitzky NA, Gutmanas EY, Claussen N. Mechanical properties of $\mathrm{Al}_{2} \mathrm{O}_{3} /$ $\mathrm{Si}$ composites fabricated by pressureless infiltration technique. Materials Lettters 1997; 33 (1-2):47-50.

12. Kroll P. Modelling polymer derived ceramics. Journal European Ceramic Society 2005; 25 (2-3):163-174.

13. Michalet T, Parlier M, Beclin F, Duclos R, Crampon J. Elaboration of low shrinkage mullite by active filler controlled pyrolysis of siloxanes. Journal European ceramic Society 2002; 22 (2):143-152.

14. Hoeland W. Biocompatible and bioactive glass-ceramic-state of the art and new directions. Journal Non-Crystalline Solids 1997; 219 (1):192-197.

15. Montedo OR, Reitz GM, Bertan FM, Oliveira APN. Extruted LZS glassceramics. American Ceramic Society Bulletin 2004; 83:9201-9206.

16. Sousa, E.; Silveira, C. B.; Fey, T.; Greil, P.; Hotza, D.; de Oliveira, A. P. LZSA glass ceramic foams prepared by replication process. Adances in Applied Ceramic 2005; 104(1):22-29.

17. Renato J. Estudo de sistemas vítreos para infiltração em alumina. [Dissertation, Pos-graduation Program of Science and Materials engineering]. Rio Grande do Norte: Federal University of Rio Grande do Norte; 2007.

18. INTERNATIONAL ORGANIZATION FOR STANDARD. ISO 10545-3 (EN 99). Determination of water absorption, apparent porosity, apparent relative density and bulk density of ceramic tiles. Genebra; 1991. 